\title{
Carcinoma Espinocelular da Mama: Relato de Um Caso
}

\author{
Squamous Cell Carcinoma of the Breast Tissue: a Case Report \\ Rubens José Pereira, Wilson Garcia Pereira, Luiz Fernando Jubé Ribeiro \\ Rita de Cássia Alencar, Vera Saddi, Geraldo Silva Queiroz \\ Ruffo de Freitas Júnior
}

\begin{abstract}
RESUM0
O carcinoma espinocelular do parênquima mamário é um tipo raro de neoplasia, representando menos de $1 \%$ de todos os carcinomas mamários. Esse trabalho relata a condução de um caso diagnosticado e tratado no Serviço de Ginecologia e Mama do Hospital Araújo Jorge/ ACCG. São discutidos a apresentação clínica, o diagnóstico e o prognóstico destes tumores.
\end{abstract}

PALAVRAS-CHAVE: Mama: câncer. Mamografia. Punção aspirativa.

\section{Introdução}

O carcinoma espinocelular (CEC) do parênquima mamário é um tumor raro, representando menos de $1 \%$ de todos os casos de carcinomas mamários ${ }^{1}$. Sua origem, apesar de não estar bem esclarecida, parece se relacionar com a ocorrência de metaplasia escamosa do epitélio ductal $^{1,2}$. No diagnóstico diferencial, é obrigatório afastar doença metastática, assim como, invasão por tumores cutâneos adjacentes ${ }^{1,2,3}$.

Neste trabalho os autores relatam a ocorrência de um caso, seu tratamento e evolução e discutem alguns aspectos ligados à sua histopatologia.

\section{Relato do Caso}

Z.A.S., 76 anos, parda, lavradora, menopausada há 19 anos, tabagista, hipertensa, gesta X para X. Veio ao Serviço de Ginecologia e Mama referindo presença de tumoração indolor na mama direita, com dois meses de evolução. O nódulo era localizado no quadrante súpero-externo (QSE) e media 7,0 × 6,0 cm. As axilas e as fossas

Serviços de Ginecologia e Mama e de Anatomia Patológica, Hospital Araújo Jorge da Associação de Combate ao Câncer em Goiás.

Correspondência:

Ruffo de Freitas Júnior.

Rua 239, 181, Setor Universitário.

74603-190 - Goiânia - GO supraclaviculares estavam livres. Seguindo o estadiamento TNM da UICC, foi classificado como: T3 No Mo (Ec 1lb). Com a suspeita de neoplasia foi solicitada uma mamografia e efetuada uma punção aspirativa por agulha fina (PAAF). A citologia mostrou a presença de células com perda da coesividade, hipercromatismo e alteração da proporção núcleo: citoplasma, sendo sugestivo de carcinoma. A mamografia evidenciou uma massa de 6,0 cm de diâmetro, de alta densidade, com espiculações e localizada no QSE da mama direita.

Com o tríplice diagnóstico positivo, a paciente foi levada para a cirurgia. O estudo histológico intra-operatório por congelação do tumor confirmou o diagnóstico de carcinoma invasor, sendo a paciente submetida à mastectomia radical modificada preservando-se o músculo grande peitoral.

O estudo anátomo-patológico revelou tratarse de um carcinoma espinocelular invasivo, grau III, com extensas áreas de necrose e com infiltrado linfoplasmocitário $+++/ 4$. As margens cirúrgicas estavam livres de neoplasia e não havia metástases nos 22 linfonodos dissecados (Figura 1).

A imuno-histoquímica diagnóstica, utilizando a técnica da streptoavidina-biotina-peroxidase, com recuperação antigênica, foi compativel com carcinoma infiltrante de ductos mamários, tipo metaplásico com componente escamoso puro (Tabela 1 e Figuras 2 e 3).

Foram realizados exames complementares (citologia oncoparasitária cervical, radiografia de tórax, endoscopia digestiva alta e exame físico 
completo de cabeça e pescoço), que afastaram outros sítios primários.

Posteriormente a paciente foi submetida a radioterapia complementar (5.040 cGy no plastrão). No momento a paciente encontra-se há 24 meses em acompanhamento e sem evidências de doença em atividade.

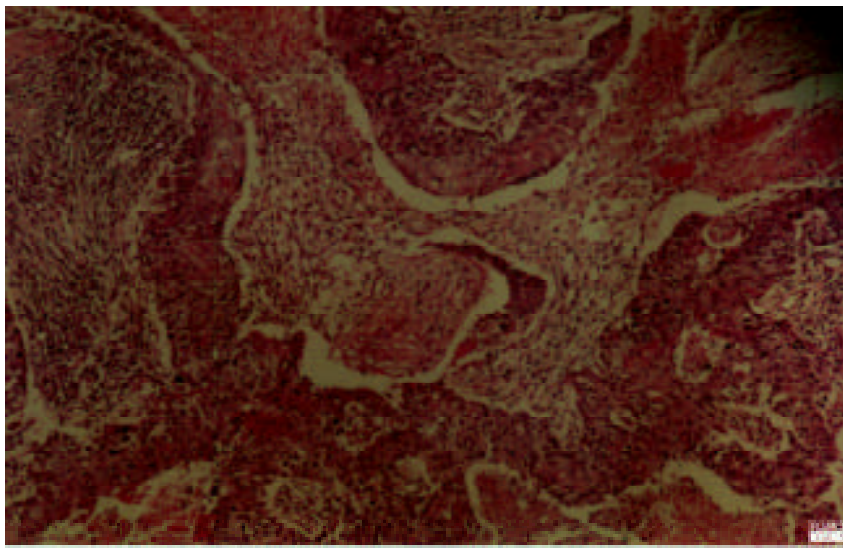

Figura 1 - Carcinoma de mama com padrão invasor (HE 40x).

Tabela 1 - Perfil imuno-histoquímico do tumor compatível com carcinoma de ductos mamários infiltrante do tipo escamoso.

\begin{tabular}{ll}
\hline \multicolumn{1}{c}{ Painel de anticorpos } & \multicolumn{1}{c}{ Resultados } \\
\hline Citoqueratina de alto peso molecular & Positivo - padrão citoplasmático \\
(3BE12) & \\
$\begin{array}{l}\text { Citoqueratina de baixo peso molecular } \\
\text { (35BH11) }\end{array}$ & Positivo - padrão citoplasmático \\
Citoqueratina 7 (OV-TL 12/30) & Positivo - Focalmente \\
Antígeno cárcino-embrionário (CEA) & Positivo - Focalmente \\
Antígeno de membrana epitelial (EMA) & Positivo - Focalmente
\end{tabular}

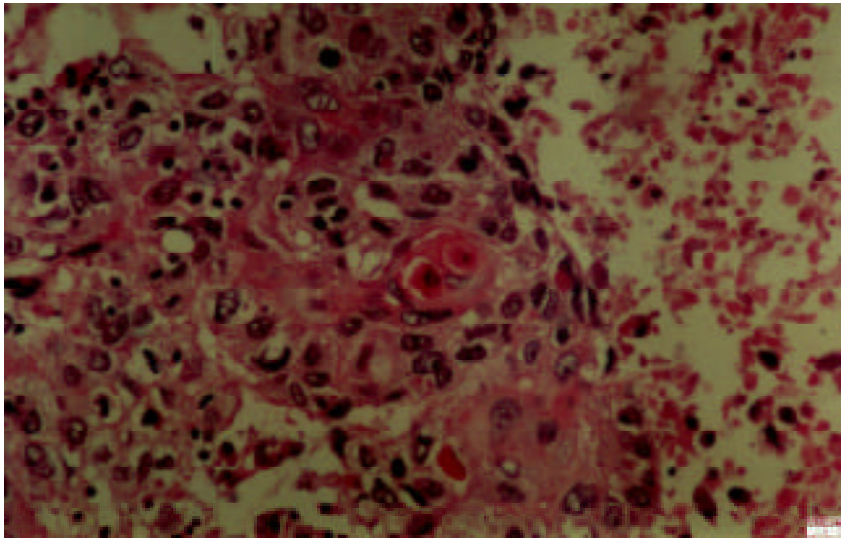

Figura 2 - Carcinoma mamário mostrando queratinização com a formação de pérolas córneas (seta) (HE 100X).

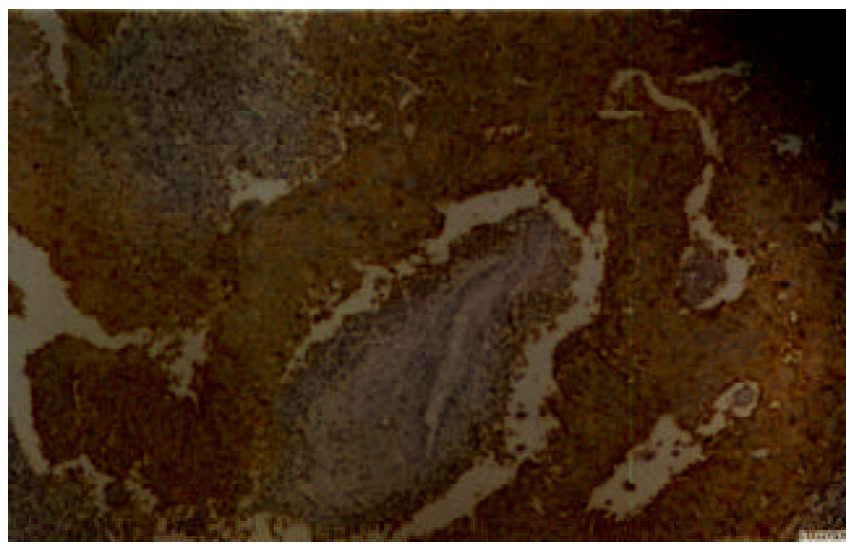

Figura 3 - Imuno-histoquímica mostrando a presença de antígeno de membrana epitelia (Ema/E-29) de padrão difuso (200X).

\section{Discussão}

O caso aqui relatado pode ser caracterizado como um CEC primário do parênquima da mama, devido à exclusão de outros sítios primários de CEC (esôfago, pulmão, colo uterino e tumores de cabeça e pescoço), à ausência de lesões cutâneas adjacentes na mama e à ausência de outros elementos além das células epidérmicas malignas ${ }^{1,2}$

A origem deste tumor não está clara, mas acredita-se que a metaplasia escamosa seja sua lesão precursora. Esta pode surgir em razão de processos inflamatórios crônicos (infartos e próteses), abscessos, hiperplasia de ductos mamários, papilomas, pós-trauma, manipulação cirúrgica ou do revestimento de cistos mamários ${ }^{1,2,4}$. Seguindo outra linha, alguns autores acreditam na possibilidade de que tais tumores sejam provenientes de alterações no desenvolvimento embrionário ${ }^{5}$.

A clínica do CEC do parênquima da mama e os achados dos exames radiológicos são semelhantes aos dos outros tipos histológicos dos carcinomas mamários ${ }^{1,5,6}$. É importante salientar que o caso aqui relatado apresentou o diagnóstico tríplice de suspeição para malignidade. A literatura mostra que a PAAF é um bom método para o diagnóstico ou suspeita de CEC do parênquima mamário, assim como a citologia da descarga mamilar, quando presente ${ }^{7}$.

Macroscopicamente os CEC de mama são tumores sólido-císticos (degeneração central) principalmente quando maiores que $2 \mathrm{~cm}$. Histologicamente são classificados dentro do grupo dos tumores metaplásicos, podendo ser puros ou mistos (adenoescamoso). Evidenciam-se núcleos irregulares, pleomórficos, hipercromáticos e aumentados de tamanho, citoplasma com leve a 
moderada tendência granulocítica, eosinofilia e tendência a ficar alaranjado, verde claro ou azul ${ }^{1,5}$. Alguns podem apresentar um padrão fusiforme associado $^{3}$. Já a imunoistoquímica, pode ajudar, uma vez que eles possuem antígenos para membrana epitelial e citoqueratina ${ }^{1,3}$. Esses marcadores puderam ser bem evidenciados no caso aqui relatado.

Quanto ao tratamento, ainda permanece em aberto qual a melhor abordagem, devido, principalmente, à sua raridade, uma vez que apenas cerca de 50 casos foram publicados ${ }^{5}$. A mastectomia associada à linfadenectomia axilar é preconizada. A radioterapia foi usada na nossa paciente e também na grande maioria dos relatos da literatura, embora de valor incerto.

O uso da quimioterapia é pouco relatado existindo descrições de boas respostas ao cisplatina e fluoracil. A grande maioria dos CEC de mama não possuem receptores hormonais. Nota-se também que a maioria das pacientes não apresentam comprometimento linfonodal independente do tamanho tumoral ${ }^{3}$. O prognóstico é semelhante aos demais tipos de carcinoma mamário ${ }^{1,5}$.

\section{SUMMARY}

Squamous cell carcinoma of the mammary tissue is a very rare neoplasm, representing less than $1 \%$ of all breast carcinomas. The present study reports a case of squamous cell carcinoma of the breast, treated at the Hospital Araujo Jorge/ACCG. The tumor diagnosis, treatment and prognosis are also discussed.

KEY WORDS: Breast: cancer. Mammography. Aspiration cytology.

\section{Referências}

1. Tavassoli FA. Infiltrating carcinoma, special types. In Tavassoli FA. Pathology of the Breast. Norwalk: Appleton \& Lange; 1992, p. 349-423.

2. Perez-Mesa CM. Gross and microscopic pathology. In Donegan WL, Spratt JS. Cancer of the Breast. $4^{\text {th }}$ ed. Philadelphia: W.B. Saunders; 1995 p. 240 78 .

3. Jin Y, Campana F, Vilcoq JR, Vielh P, Schlienger P, Matthieu G, et al. Carcinome épidermoide primitif du sein. Etude clinique, histopathologique et pronostique de 14 patientes. Bull Cancer (Paris) 1992; 79: 675-9.

4.Talmor M, Rothaus KO, Schannahan E, Cortese AF, Hoffman LA. Squamous cell carcinoma of the breast after augmentation with liquid silicone injection. Ann Plast Surg 1995; 34: 619-23.

5. Samuels TH, Miller NA, Manchul LA, Defreitas G, Panzarella T. Squamous cell carcinoma of the breast. Can Assoc Radiol J 1996; 47: 177-82.

6. Senga O, Hikita H, Kinoshita T, Hara K, Miyakawa $\mathrm{M}$, Nishimura $\mathrm{H}$, et al. Primary squamous cell carcinoma of the breast in a pregnant woman: report of a case. Surg Today 1993; 23: 541-5.

7. Nakayama $K$, Abe $R$, Tsuchiya A, Watanabe $T$, Furukawa Y, Nihei M, et al. Squamous cell carcinoma of the breast, report of a case diagnosed by fine needle aspiration cytology. Acta Cytol 1993; 37: 961-5. 